\title{
Commentary \\ Sex Differences in Self-Estimated Intelligence, Competitiveness and Risk-Taking
}

\author{
Adrian Furnham* \\ University College London, UK \\ *Address for correspondence: Furnham@ucl.ac.uk
}

Studies of self-estimated intelligence have consistently shown that males estimate their intelligence higher than do females, and people estimate the intelligence of male family members higher than that of female family members. A number of studies have also shown that males are more competitive and greater risk-takers than females.

\section{Key Words: Sex differences, Self-confidence, Intelligence}

Richard Lynn has written a convincing, thoroughly empirically based paper in one of the "hottest" areas of psychology. To suggest there are group differences in intelligence will cause more "debate" than practically any other issue in psychology. He is well known for his courageous stand, always based on hard data.

I want to add two comments to the debate. Presuming that males are "somewhat" more intelligent than females, the question is how this translates into the obviously greater success of males than females in so many areas of life such as creativity in the arts and sciences, as well as in business. Whilst there are numerous sociological arguments to "explain" this situation, I want to suggest two further points related to his paper.

The first concerns intellectual self-confidence or self-estimated IQ. I have published many papers and have data from 30 countries from Argentina to Zambia that suggests there is a universal finding that men estimate their own IQ as 3-10 points higher than females (e.g. Furnham, 2000; Furnham \& Bunclark, 2006; Furnham \& Shagabutdinova, 2012; Szymanowicz \& Furnham, 2011). Lynn would no doubt argue that this reflects reality, though others of course would argue that it is because of their socialization: Boys are encouraged to brag about and girls to hide their intelligence. Whatever the cause, there are few studies from any country that do not support the finding that males estimate their $I Q$, understood as "general intelligence" rather than "multiple intelligences", higher than do females.

Whether this difference reflects an actuality or not, there is considerable evidence that self-beliefs can be selffulfilling. To quote Henry Ford: "Whether you think you can, or you think you can't-you're right." Thus it may be that male achievement in so many aspects of life can in part be attributed to their self-belief in their intelligence which may (or may not) accurately reflect their actual ability. In a study at the University of Oxford, three female dons led by Jane Mellanby showed that consistent male domination of the top marks was due mainly to academic self-confidence (Mellanby, Martin \& O'Doherty, 2000). Thus self-belief, whatever it is based on, has manifold consequences.

A question which arises from the self-estimated intelligence literature is whether the sex difference, if not real, is due to male hubris or female humility. Do males over-estimate or women under-estimate their actual IQ, or both? There are not enough good studies with both self-estimated and test-derived IQ to settle the argument.

The second issue is competitiveness vs cooperativeness, and general risk-taking. There is a considerable amount of data from evolutionary and social psychology to suggest that males are more competitive than females. Again, there is a dispute as to whether this difference is predominantly biologically based or the product of socialization, but there are numerous studies to support this effect. Males are more competitive, and females are more cooperative.

Further, this competitiveness is linked to risk-taking. It is for this reason that males tend to be more involved in accidents and in entrepreneurial, criminal and military adventures. Thus, if males are more desirous to succeed (achievement orientation), willing to put in the effort, and risk a great deal in the process, it is not surprising that they have a greater success rate in many fields including the achievement of academic competence, which requires the development of high intelligence.

\section{References}

Furnham, A. (2000). Parents' estimates of their own and their children's multiple intelligences. British Journal of Developmental Psychology 18: 583-594. 
Furnham, A. \& Bunclark, K. (2006). Sex differences in parents' estimations of their own and their children's intelligence. Intelligence 34: 1-14. 
MANKIND QUARTERLY 2017 58:1

Furnham, A. \& Shagabutdinova, K. (2012). Sex differences in estimating multiple intelligences in self and others. International Journal of Psychology 47: 1-12.

Mellanby, J., Martin, M. \& O'Doherty, J. (2000). The 'gender gap' in final examination results at Oxford University. British Journal of Psychology 91: 377-390.

Szymanowicz, A. \& Furnham, A. (2011). Gender differences in self-estimates of general, mathematical, spatial, and verbal intelligence: Four meta-analyses. Learning and Individual Differences 21: 493-504. 